\title{
Harmonization of different type of coordinate systems used for North Macedonian official spatial data
}

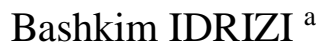 \\ a University of Prishtina “Hasan Prishtina”, bashhkim.idrizi@yahoo.com,bashkim.idrizi@uni-pr.edu, bashkim.idrizi@unt.edu.mk
}

\begin{abstract}
From the beginning of developing vector data sets in Macedonia, till now, three type of coordinate values for North Macedonian spatial data have been used.

Law for real estate cadaster and Regulation for basic geodetic works are the official legal bases for definition of official state coordinate system. In both legal documents, state coordinate system is defined by Ellipsoid of Bessel 1841, Datum of Hermannskogel, and Gauss-Kruger projection with central meridian $21^{\circ} \mathrm{E}$, scale factor 0.9999 , false easting $500000 \mathrm{~m}$, false northing $0 \mathrm{~m}$ and 7 th projecting zone per $3^{\circ}$. Based on mentioned parameters, the coordinate systems EPSG 6204 and EPSG 6316 are defined and internationally recognized. The core deferens between them is false easting value. As a result of both coordinate systems parameters, the values of easting coordinates are far from each other for $7000 \mathrm{~km}$ !
\end{abstract}

Beside EPSG 6204 and 6316, official spatial data sets defined in CAD software were digitized by excluding first digits of easting and northing coordinates, by excluding digits 7 for easting and 4 for northing coordinates of spatial data.

Using three types of coordinate values, requires process of data harmonization before their usage in same project, in order to reach the spatial data overlapping. Third type of coordinate system, due to the lack of coordinate system parameters, can not be automatically overlapped with data defined in EPSG6204 and EPSG6316, which requires defining of intermediate coordinate system for third type of data in order to establish the mathematical base for data harmonization/overlapping by transformation of coordinates between three systems.

Keywords: Data harmonization, coordinate system, transformation, parameters

\section{Introduction}

The reference coordinate system of the North Macedonia, was established in the third decade of nineteenth century, as part of Kingdom of Yugoslavia, performed by the Military Geographic Institute in Belgrade.

Geodetic datum of the Austro-Hungarian monarchy, based on fundamental point Hemrannskogel in the hill near Vienna in Austria (figure 1), have been used as basement for establishing of state coordinate system of Kingdom of Yugoslavia. Coordinates of the fundamental point are determined by astronomical methods and are summarized as follows (Mulić, 2018):

- $\quad$ astronomical latitude $\varphi=48^{\circ} 16^{\prime} 15.29 " \pm 0.04$ ”;

- $\quad$ astronomical longitude $\lambda=33^{\circ} 57^{\prime} 41.06^{\prime \prime} \mathrm{E}$ of the Ferro,

- the network orientation is defined by the azimuth of the trigonometric line "Hermannskogel - Hundsheimer Berg" $\alpha=107^{\circ} 31^{\prime} 41.7^{\prime \prime}$.

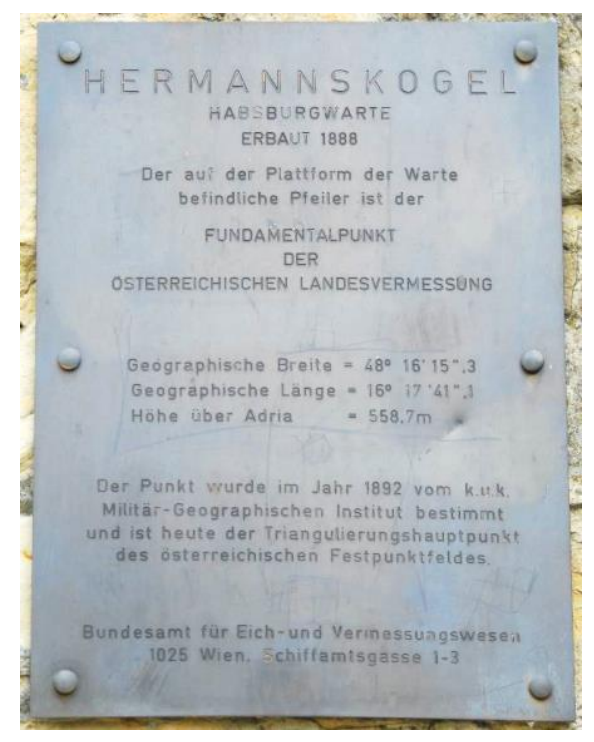

Figure 1. Table of the Hermannskogel fundamental point on the Habsburgwarte (Http 1)

The Bessel 1842, as in the most Central European counties in that period, was used as reference ellipsoid. For the cartographic purposes, Gauss-Krüger (transverse, cylindrical and conformal) projection, with the $3^{\circ}$ 
projecting meridian zones $\left(15,18\right.$ and $\left.21^{\circ} \mathrm{E}\right)$, based on the Greenwich as reference (prime) meridian, with linear scale 0.9999 along the central meridians (secant projection case) and false easting value of $500000 \mathrm{~m}$ for each projecting zone, was adopted in year 1924 for the whole Kingdom of Yugoslavia (Idrizi, Pashova et all 2018). In next figure 2, coverage of the area of former Yugoslavia with $5^{\text {th }}, 6^{\text {th }}$ and $7^{\text {th }}$ projecting zones, based on central meridians 15,18 and $21^{\circ} \mathrm{E}$ is shown.

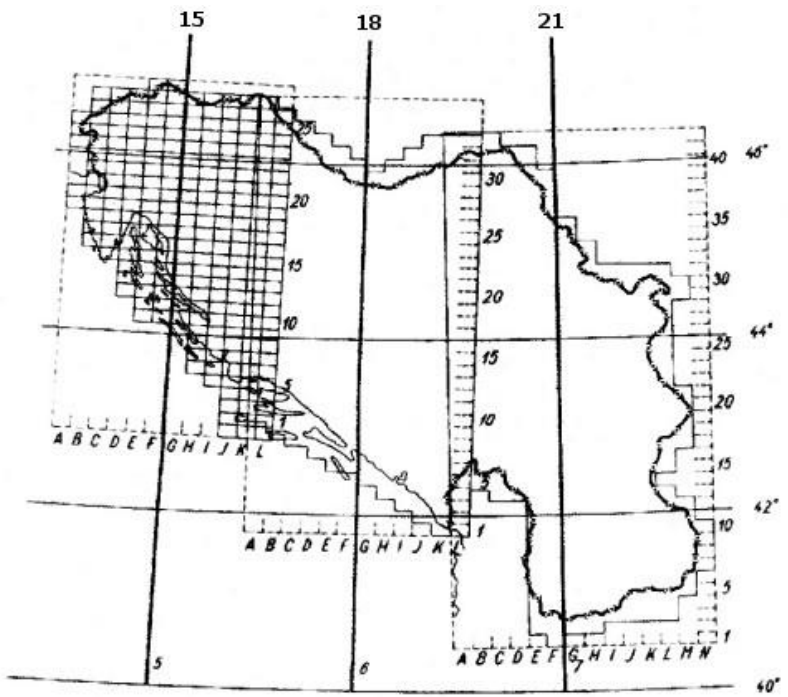

Figure 2. Coordinate systems used in the former Yugoslavia, division in zones, based on the central Meridians (Http 2)

In order to distinguish coordinate values between points in three projecting coordinate zones in former

Yugoslavia, values for easting coordinates contains the number of projecting zone (5, 6 or 7 ) as first digit. This means that easting coordinates in $5^{\text {th }}$ zone (based on central meridian $15^{\circ} \mathrm{E}$ ) begins with digit 5 , easting coordinates in $6^{\text {th }}$ zone (based on central meridian $18^{\circ} \mathrm{E}$ ) begins with digit 6 , while the easting coordinates in $7^{\text {th }}$ zone (based on central meridian $21^{\circ} \mathrm{E}$ ) begins with digit 7. The territory of North Macedonia belongs to the $7^{\text {th }}$ projecting zone (Idrizi 2014).

The $7^{\text {th }}$ zone of this coordinate system is still in use in North Macedonia as official state coordinate system.

A part of Slovenian area west of the meridian $16^{\circ} 30^{\prime} \mathrm{E}$, as well areas of Serbia and North Macedonia east of meridian $22^{\circ} 30^{\prime}$, theoretically doesn't belongs to $5^{\text {th }}$ and $7^{\text {th }}$ projecting zones, since the western point of Slovenian territory is along meridian $13^{\circ} 23^{\prime} \mathrm{E}$ (Http 3), eastern point of Serbia is located in $23^{\circ} 01^{\prime} \mathrm{E}$ (Http 4), while the eastern point of North Macedonia is located along meridian $23^{\circ} 02^{\prime} \mathrm{E}$ (Http 5). Entire area between $13^{\circ} 30^{\prime} \mathrm{E}$ and $13^{\circ} 23^{\prime} \mathrm{E}$ belongs to $4^{\text {th }}$ projecting zone, while the area between $22^{\circ} 30^{\prime} \mathrm{E}$ and $23^{\circ} 02^{\prime} \mathrm{E}$ belongs to $8^{\text {th }}$ projecting zone. However, in order to avoid using separate projecting zones for very small areas, western area of Slovenia was joined to $5^{\text {th }}$ projecting zone, while eastern areas of Serbia and North Macedonia were joined to $7^{\text {th }}$ projecting zone, even though the distortions in map projection exceeded the value of $10 \mathrm{~cm} / \mathrm{km}$.

\section{State coordinate system of the Republic of North Macedonia}

From the third decade of last century, up to nowadays, about one century, the official state coordinate system of the Republic of North Macedonia is using still the same coordinate system defined by the Military Geographic Institute in Belgrade, except the value of false easting. The parameters of current state coordinate system are defined in the articles 41 and 42 of the Law for real estate cadaster (Official gazette no.55, year 2013), articles 6, 7 and 8 of the Regulation for compilation of topographic maps, ortho photo maps/plans and cartographic products (Official gazette no.159, year 2013), as well in the articles 23, 24, and 26 of the regulation for basic geodetic works (Official gazette no.151, year 2013). In table 1, parameters of the state coordinate of the North Macedonia are given.

\begin{tabular}{|l|l|}
\hline Datum & Hermannskogel \\
\hline Ellipsoid & Bessel 1841 \\
\hline Map projection & Gauss-Kruger $\left(3^{\circ}\right.$ zones $)$ \\
\hline Central meridian & $21^{\circ} \mathrm{E}$ \\
\hline Prime meridian & Greenwich \\
\hline Origin of latitude & Equator \\
\hline Scale factor & 0.9999 \\
\hline False easting & $500000 \mathrm{~m}$ \\
\hline False northing & $0 \mathrm{~m}$ \\
\hline Units & $\mathrm{m}($ meter $)$ \\
\hline Projecting zone & $7^{\text {th }}$ zone \\
\hline
\end{tabular}

Table 1. Parameters of North Macedonian state coordinate system (Idrizi, Ribarovski, 2010)

Above given parameters of the state coordinate system are defined in all laws and regulations for basic geodetic works and/or laws and regulations for cadastral/topographical surveying from year 1920 until 2013 also, such as Law for land cadaster (official gazette no.34, year 1972), regulation for basic geodetic works (official gazette no.85, year 2007) etc, with just one difference with the current one, where $7500000 \mathrm{~m}$ was used as value for the false easting.

After the independence of the Republic of North Macedonia in year 1991, usage of digit 7 in easting coordinate values, became insignificant digit, due to usage of one unique projecting zone for entire state territory, inherited from the $7^{\text {th }}$ projecting zone of the former Yugoslavia. The insignificance of digit 7 in easting coordinate is clearly shown in table 1 , as well in article 42 of the Law for real estate cadaster (Official gazette no.55, year 2013), article 7 of the Regulation for compilation of topographic maps, ortho photo maps/plans and cartographic products (Official gazette no.159, year 2013) 
and article 26 of the regulation for basic geodetic works (Official gazette no.151, year 2013), where the value of false easting is $500000 \mathrm{~m}$, instead $7500000 \mathrm{~m}$ from former Yugoslavia. Based on the false easting value defined in the above mentioned Law and Regulations, easting coordinates in the state coordinate system of the North Macedonia should exclude digit 7, which means that easting coordinates should contain six digits in meters.

Since the coordinate system is inherited from former Yugoslavia, it is internationally known as "MGI/Balkans zone 7" with code EPSG 31277 (+proj=tmerc +lat_0=0 + lon_0 $=21+\mathrm{k}=0.9999+\mathrm{x} \_0=7500000+\mathrm{y} \_0=0$ +ellps=bessel +units $=\mathrm{m}$ +no_defs), as well as "MGI 1901/Balkans zone 7" with code EPSG 3909 (+proj=tmerc +lat_0 $=0+$ lon_0 $=21+\mathrm{k}=0.9999+\mathrm{x} \_0=7500000+\mathrm{y} \_0=0$ +ellps $=$ bessel + units $=\mathrm{m}+$ no_defs $)$. In both coded EPSG coordinate reference systems, false easting has the same value of $7500000 \mathrm{~m}$.

North Macedonians state coordinate system as independent country is defined and internationally recognized by EPSG database for coordinate systems worldwide with codes 6316 and 6204 (https://epsg.org). The difference between both coordinate reference systems is the value of false easting, i.e. EPSG 6204 is defined based on the Law with $500000 \mathrm{~m}$ false easting (+proj=tmerc +lat_0 $=0 \quad+$ lon_0 $=21 \quad+\mathrm{k}=0.9999$ $+\mathrm{x} \_0=500000+\mathrm{y} \_0=0+\mathrm{ellps}=$ bessel + units $=\mathrm{m}+$ no_defs $)$, while the EPSG 6316 is defined with non-legal false easting value $7500000 \mathrm{~m}$ (+proj=tmerc +lat_0 $=0$ +lon_0 $=21+\mathrm{k}=0.9999+\mathrm{x} \_0=7500000+\mathrm{y} \_0=0$ +ellps=bessel + units $=\mathrm{m}+$ no_defs) based on coordinate reference system inherited from the former Yugoslavia with three projecting zones by using $7500000 \mathrm{~m}$ as false easting. Both coordinate systems now are usable in GIS software, as standardized CRS.

Republic of North Macedonia, together with Republic of Bosnia and Herzegovina, are the last countries in Balkan peninsula who are using still the old coordinate systems, and still didn't adopt fully the new coordinate reference system based on the datum ETRS89.

\section{Coordinate reference systems used for spatial data in the North Macedonia}

The official spatial data for the area of North Macedonia after the first world war, firstly as part of Kingdom of Yugoslavia, then as part of SFR Yugoslavia, and after year 1991 as independent country, have been developed based on the State Coordinate System defined by the Military Geographic Institute on year 1924, shown in table 1 , except the false easting and false northing values. Even though the parameters were clearly defined, due to usage of number of digits for representing and calculating point coordinates, three coordinate reference systems were recognized in practice, with the difference only in the values of false easting and false northing.

Within first coordinate system, based on the parameters from former Kingdom of Yugoslavia, easting and northing coordinate values contains per 7 (seven) digits in meters. This system is internationally recognized as "MGI/Balkans zone 7" with code EPSG 31277, as well as “MGI 1901/Balkans zone 7" with code EPSG 3909. Such a system is still in use in Macedonia, even after its independence, which now is internationally recognized with EPSG code 6316. The official geoportals of the North Macedonia for distribution of spatial data and NSDI (https://ossp.katastar.gov.mk/OSSP and http://nipp.katastar.gov.mk/geoportal/) are based on this coordinate reference system, even though it doesn't use the same value of false easting as it is defined in state legislation (above mentioned Law and Regulations). In figure 3, an example with the spatial data in EPSG 6316 is given, while in figure 4 the example from the North Macedonian NSDI geoportal is given where the nonexisting of difference between coordinates in state coordinate system (EPSG 6316) and in the Gauss-Kruger zone 7 (EPSG 32177 and EPSG 3909) can be recognized.

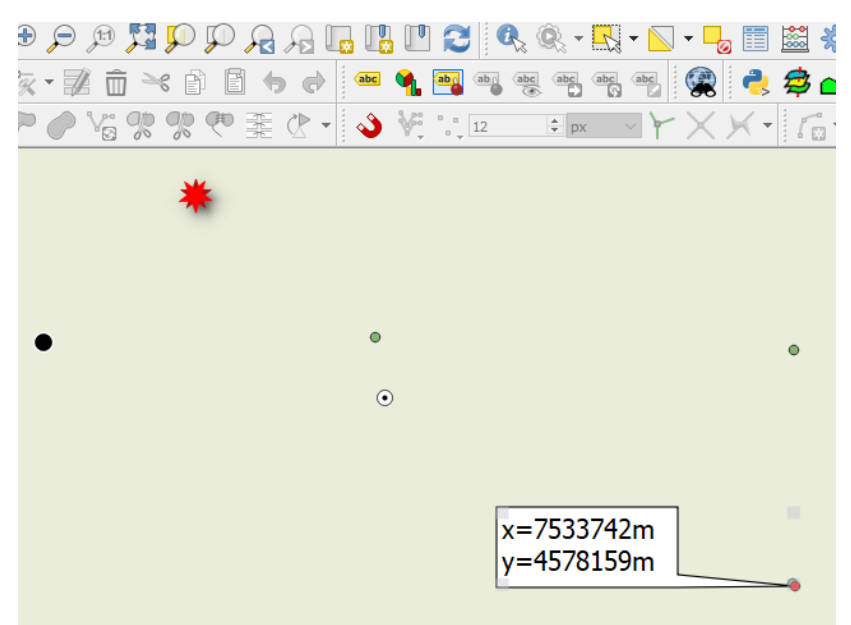

Figure 3. Example of spatial data in EPSG 6316 


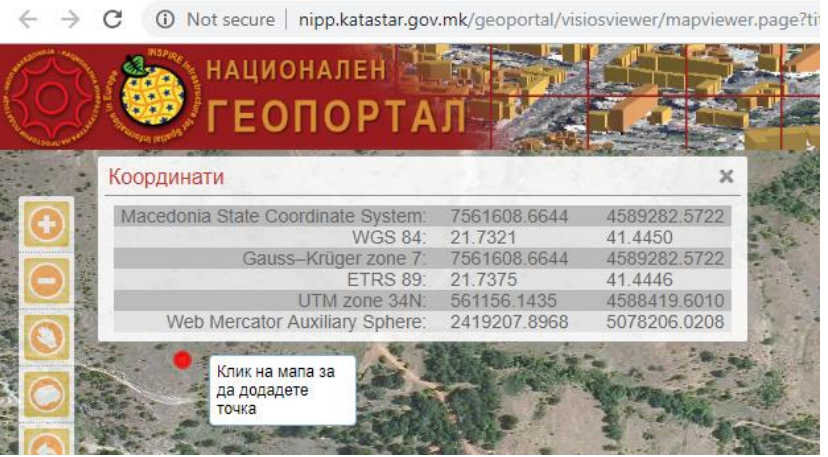

Figure 4. Extract from the NSDI geoportal of North Macedonia (http://nipp.katastar.gov.mk/geoportal)

Even though the digit 7 (seven) in easting coordinate was excluded after the independence of North Macedonia, as it represented the number of projecting zone in former Yugoslavia, few spatial data sets have been developed in this coordinate reference system, which is internationally coded as EPSG 6204. In figure 5, an example with the spatial data developed in EPSG 6204 is shown. Easting coordinates of spatial data contains 6 (six) digits in meters, as the only difference with previous one EPSG 6316, which affects the data being far from each other by $7000 \mathrm{~km}$, shown in figure 7 .
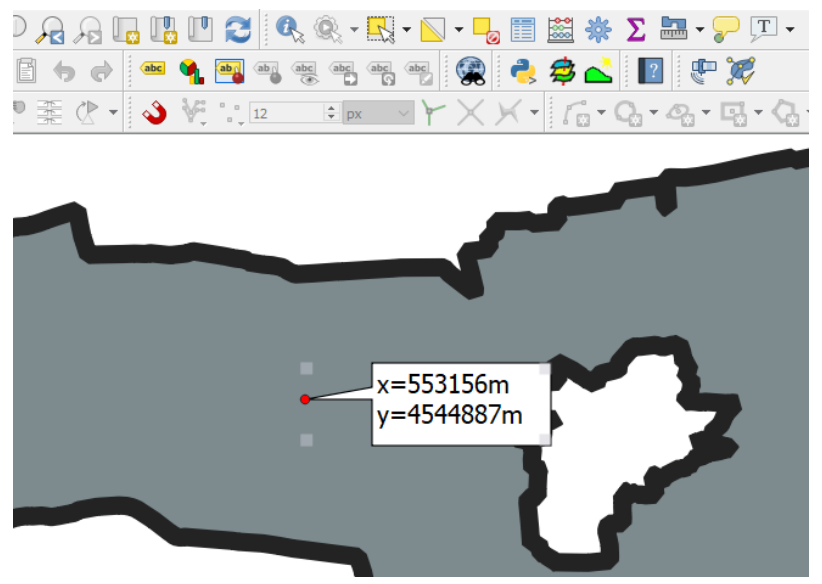

Figure 5. Example of spatial data in EPSG 6204

Beside both internationally recognized coordinate reference systems (EPSG 6204 and 6316), official spatial data sets defined in past period, especially in Microstation software in Agency for Real Estate Cadastre, were digitized by excluding first digits of easting and northing coordinates. Practically this means not using digits 7 for representing of easting coordinates and 4 for representing of northing coordinates of spatial data. This type of coordinate representing has been used for georeferenced raster data also, such orthophoto maps etc. In figure 6, an example of ortho photo image defined with 6 digit coordinates in meters, out of parameters defined in Law and Regulation, is shown. Such a kind of data type is far from EPSG 6316 for $7000 \mathrm{~km}$ in easting and $4000 \mathrm{~km}$ in northing, as well $4000 \mathrm{~km}$ far from data developed in EPSG 6204, shown in figure 7.

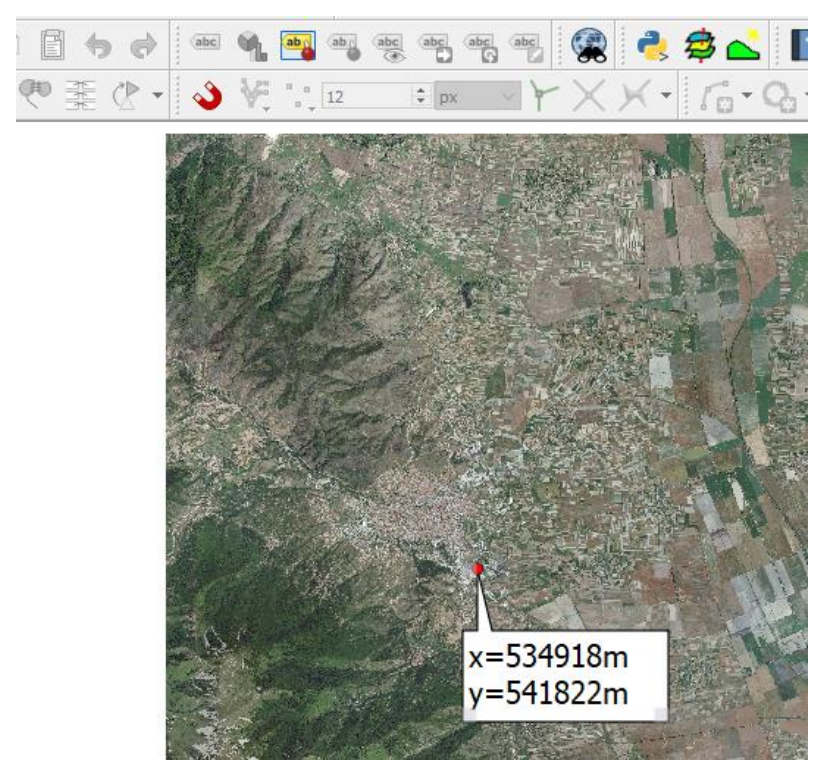

Figure 6. Example of spatial data in nonofficial CRS, by excluding digit 7 in easting and 4 in northing coordinates

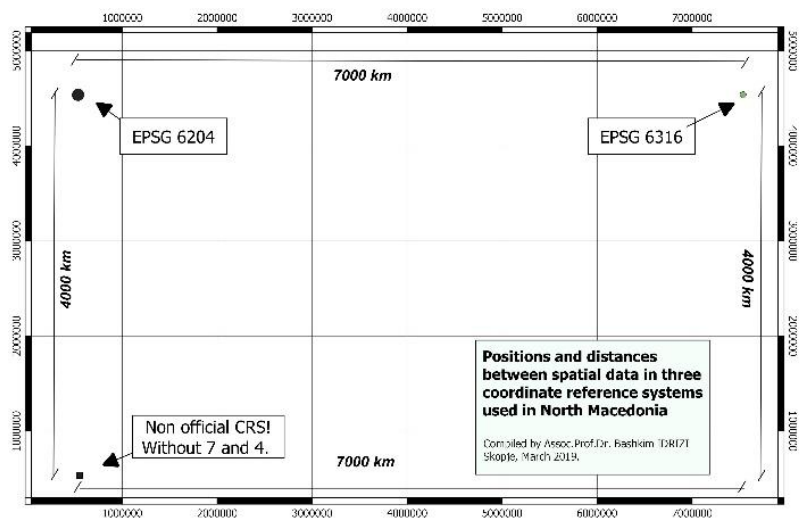

Figure 7. Positions and distances between spatial data in three coordinate reference systems used in North Macedonia

\section{Defining third coordinate reference system for data developed by excluding digit 7 from easting and digit 4 from northing coordinates}

Due the most of data defined in non-official and nonstandardized coordinate reference system were in CAD software (Microstation), in which defining of coordinate reference system is not required by the software, data harmonization with other data defined in standardized coordinate systems EPSG 6316 and 6204 have been performed by simple moving of the spatial data for $7000 \mathrm{~km}$ along the abscissa (easting) and/or 4000km along ordinate (northing). The distances are shown in figure 7.

In order to use this kind of data in GIS software without the need for previous moving steps of all data separately one by one for $7000 \mathrm{~km}$ and/or $4000 \mathrm{~km}$ in CAD software, the need for defining of new coordinate reference system for third data type was emerged. The mathematical model defined through parameters of new intermediate coordinate reference system will enable automatic 
overlapping of spatial data with another official data developed in one of the internationally coded systems EPSG 6316 and 6204, by using ON THE FLY mode. Parameters of new coordinate system are shown in table 2.

\begin{tabular}{|l|l|}
\hline Datum & Hermannskogel \\
\hline Ellipsoid & Bessel 1841 \\
\hline Map projection & Gauss-Kruger $\left(3^{\circ}\right.$ zones $)$ \\
\hline Central meridian & $21^{\circ} \mathrm{E}$ \\
\hline Prime meridian & Greenwich \\
\hline Origin of latitude & Equator \\
\hline Scale factor & 0.9999 \\
\hline False easting & $500000 \mathrm{~m}$ \\
\hline False northing & $-4000000 \mathrm{~m}$ \\
\hline Units & $\mathrm{m}(\mathrm{meter})$ \\
\hline Projecting zone & $7^{\text {th }}$ zone \\
\hline
\end{tabular}

Table 2. Parameters of coordinate reference system for North Macedonian spatial data defined with 6 digits in meter, by excluding digits 7 from easting and 4 from northing coordinate system

In figure 8 the spatial positions and parameters of three coordinate reference systems for North Macedonia are shown, where the third system is defined based on the parameters from table 2 (+proj=tmerc +lat_ $0=0$ + lon_0 $=21+\mathrm{k}=0.9999+\mathrm{x} \_0=500000+\mathrm{y} \_0=-4000000$ +ellps=bessel +units=m +no_defs).

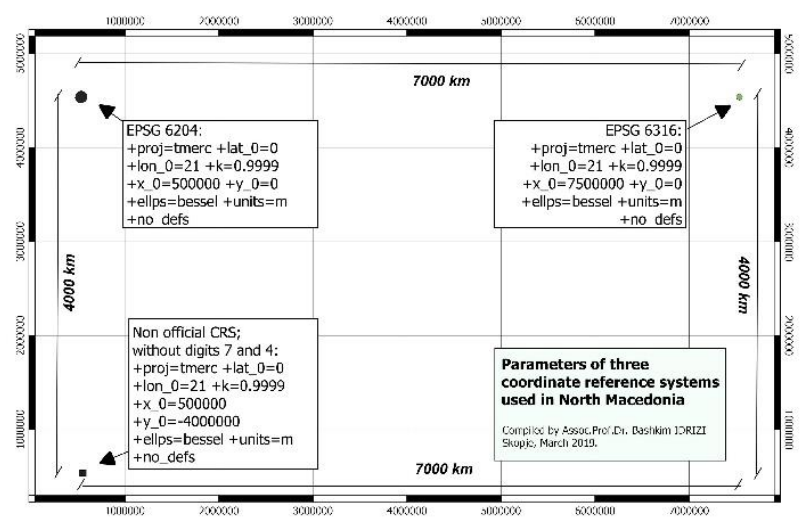

Figure 7. Positions, distances and parameters for/between spatial data in three coordinate reference systems used in North Macedonia

Third reference coordinate system should be internationally recognized within EPSG database for coordinate systems worldwide with separate code, where should be mentioned "without 7 and 4", in order to be usable via GIS software automatically.

\section{Conclusions}

From the beginning of developing vector data sets in North Macedonia, by vectorizing of cadastral paper maps in CAD software, until nowadays the era of establishing
SDI's in different levels, three type of coordinate values for North Macedonian spatial data have been used.

Law for real estate cadaster, Regulation for basic geodetic works and the Regulation for compilation of topographic maps, ortho photo maps/plans and cartographic products are the official legal bases for definition of official state coordinate system. In three legal documents, North Macedonian state coordinate system is defined by Ellipsoid of Bessel 1841, Datum of Hermannskogel, and Gauss-Kruger projection with central meridian $21^{\circ} \mathrm{E}$, scale factor 0.9999 , false easting $500000 \mathrm{~m}$, false northing $0 \mathrm{~m}$ and 7 th projecting zone per $3^{\circ}$. Based on mentioned parameters, the coded coordinate reference systems EPSG 6204 and EPSG 6316 are defined and internationally recognized as official North Macedonian state coordinate reference systems.

The core deferens between both coordinate systems is value of false easting. In EPSG 6204 false easting is $500000 \mathrm{~m}$ based on the coordinate system definition in law and regulations, while in EPSG 6316 the false easting is $7500000 \mathrm{~m}$ by adding number of 7 th projecting zone as coordinate value. As a result of both coordinate systems parameters, values of northing coordinate in both systems are equal and contain seven digits, meanwhile the values of easting coordinates are far from each other for $7000 \mathrm{~km}$ because in EPSG 6204 coordinates contain six digits while in EPSG 6316 contain seven digits.

Beside both coordinate systems (EPSG 6204 and 6316), official spatial data sets defined in CAD software were digitized by excluding first digits of easting and northing coordinates. Practically this means not using digits 7 for representing of easting coordinates and 4 for representing of northing coordinates of spatial data. This kind of digitizing in CAD software, where defining of coordinate system parameters is not necessary as it is in GIS software, resulted digital maps where easting and northing coordinates contains per six digits in meters. This type of coordinate representing has been used for georeferenced raster data also, such orthophoto maps etc.

Using three types of coordinate values, requires process of data harmonization before their usage in same project, in order to reach the spatial data overlapping. Since the coordinate systems are clearly defined in EPSG 6204 and 6316, using FLY MODE of GIS software enables automatic overlapping spatial data in same coordinate system, in EPSG 6204, in EPSG 6316 or in third coordinate system. However, third type of coordinate system due to the lack of coordinate system parameters, can not be automatically overlapped with data defined with both above systems (6204 and 6316).

The new intermediate coordinate system for third type of spatial data, in order to establish the mathematical base for data harmonization by transformation of coordinates between three systems, was established with next parameters + proj=tmerc +lat $0=0 \quad+$ lon $0=21$ $+k=0.9999+x \quad 0=500000+y \quad 0=-4000000+$ ellps $=$ bessel + units $=m+n o \_$defs, that are given in table 2 also. 
Defining of this coordinate reference system for third type of data where digits 7 and 4 are missing, will have direct positive impact on the practical usage of official datasets in GIS software, and will enable automatic transformation as well "on the fly" spatial overlapping of different spatial data developed in three coordinate reference systems in North Macedonia, which should be internationally recognized and registered in EPSG database for coordinate systems worldwide as third official coordinate reference system.

\section{References}

Mulić, M. 2018. Geodetski referentni sistemi. University of Sarajevo, Faculty of Civil Engineering. Sarajevo, pp 232. ISBN 978-9958-638-50-3

Idrizi B., Ribarovski R. 2010. Historical overview, quality and current condition of the geodetic networks in Macedonia. FIG WW 2010. Sydney. Australia.

Idrizi B. 2014. Length differences between topography and map projections; case study: country area of Macedonia. Proceedings. $5^{\text {th }}$ International Conference on Cartography. Riviera. Bulgaria.

Idrizi B., Pashova L. et all. 2018. Study of length differences from topography to map projection within the state coordinate systems for some countries on the Balkan Peninsula. FIG working week. Istanbul. Turkey.

Official gazette no55. Year 2013. Law for real estate cadaster. Agency for real estate cadaster. Skopje. North Macedonia.

Official gazette no151. Year 2013. Regulation for basic geodetic works. Agency for real estate cadaster. Skopje. North Macedonia.

Official gazette no.159. Year 2013. Regulation for compilation of topographic maps, ortho photo maps/plans and cartographic products. Skopje. North Macedonia.

Official gazette no34. Year 1972. Law for land cadaster. Agency for real estate cadaster. Skopje. North Macedonia.

Official gazette no85. Year 2007. Regulation for basic geodetic works. Agency for real estate cadaster. Skopje. North Macedonia.

\section{HTTP:}

1. https://de.wikipedia.org/wiki/Datum_Austria (March 2019)

2. http://spatialanalyst.net/wiki/index.php/MGI_/_Balkans_coordinate_syst ems (March 2019)

3. https://en.wikipedia.org/wiki/Extreme_points_of_Slovenia (March 2019)

4. https://en.wikipedia.org/wiki/List_of_extreme_points_of_Se rbia (March 2019)

5. https://www.igeografija.mk/Portal/?p=9508 (March 2019)

6. https://epsg.org (March 2019)

7. http://katastar.gov.mk (March 2019) 